\title{
Clinicopatbological Conference
}

\section{A Case of Endocrine Dysfunction with Lung Carcinoma}

\author{
PRESENTED AT THE ROYAL POSTGRADUATE MEDICAL SCHOOL
}

\section{Clinical History}

Dr. G. W. Poole (1): This conference concerns a woman (Case No. 339717) aged 61 years at the time of her death. She was a dressmaker, and there was no history of previous illness. On 1 April 1968 the patient was admitted to another hospital with a history of several days' cough, purulent sputum, dyspnoea, and pain in the right chest. A diagnosis of acute respiratory infection with pleurisy was made. There was a good response to tetracycline and the patient was discharged five days later. On 14 May the patient was referred to the Hammersmith Chest Clinic and admitted to Hammersmith Hospital on 16 May. Though much improved she still had some malaise, and a little persistent cough and sputum. During the preceding three weeks she had gained some weight, had had polyuria and polydipsia and slight ankle oedema. She had smoked 15 cigarettes daily for 25 years.

She was a fit, cheerful woman, $114 \mathrm{lb}$. $(52 \mathrm{~kg}$.) in weight. The face was somewhat full, possibly because the jugular venous pressure was raised. There were some crepitations in the right chest anteriorly, while the chest radiograph showed a large mass in the right upper lobe; the blood pressure was $180 / 90 \mathrm{~mm}$. Hg., while the urine contained $0.25 \%$ sugar.

Bronchoscopy on 17 May showed a carcinoma apparently originating in the right upper bronchus and involving the right main bronchus and the carina. The carcinoma was considered to be inoperable. Bronchial biopsy showed an oatcell carcinoma (Fig. 1). The serum potassium was $2.0 \mathrm{mN}$ and bicarbonate $36 \mathrm{mN}$. A glucose tolerance test showed a diabetic curve, while the E.C.G. showed flat $T$ waves in leads I, II, V5, and V7 but unfortunately this was not taken until after 48 $\mathrm{mEq}$ of potassium had been given by mouth.

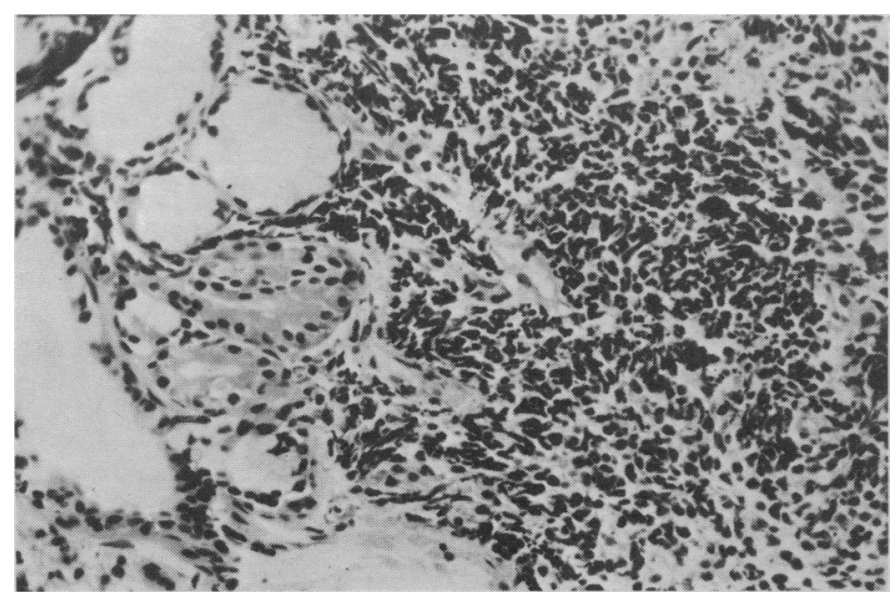

FIG. 1.-Bronchial biopsy showing oat-cell carcinoma (slightly traumatized) invading around bronchial glands. (H. and E. $\times 260$.)
The first graph (Fig. 2) shows a low potassium at $2 \mathrm{mN}$ and $2.4 \mathrm{mN}$ rising to the normal range (shown by the shaded area) after treatment with Slow-K equivalent to $96 \mathrm{mEq} / 24 \mathrm{hrs}$. When this treatment was discontinued the potassium fell to $2.3 \mathrm{mN}$, rising again when the Slow-K was started again. The plasma bicarbonate, initially high, fell to the normal range with the improvement in serum potassium. All these features-the hypokalaemia, alkalosis, diabetes, and histological

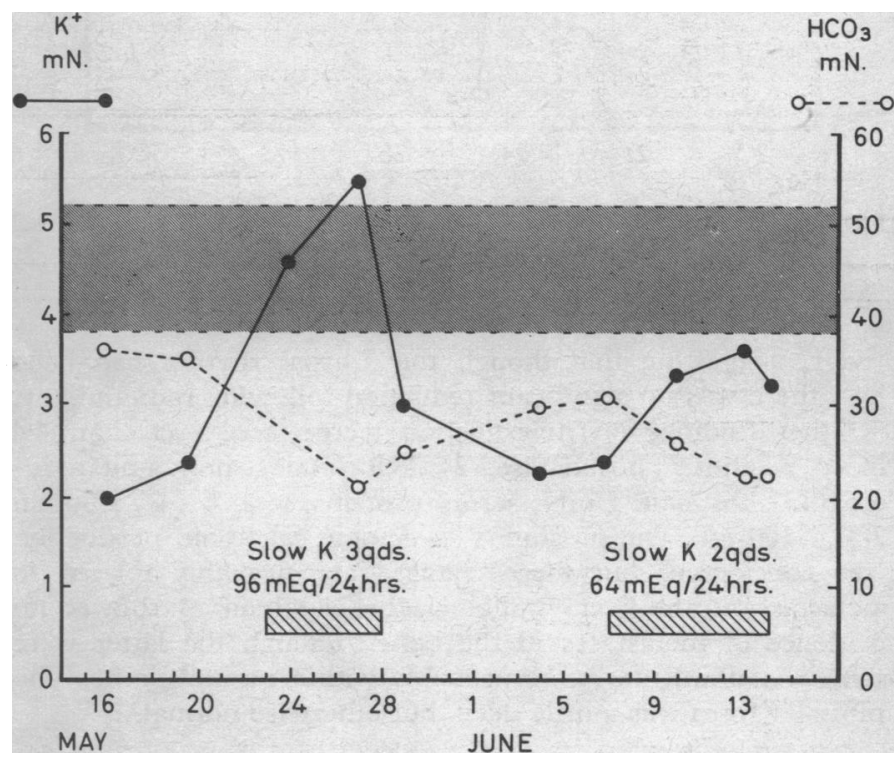

FIG. 2.-Potassium and bicarbonate levels during hospital admission.

finding of an oat-cell tumour-suggested that the tumour might be secreting A.C.T.H.

The second graph (Fig. 3) shows urine free cortisol basal levels, which were extremely high at $5 \mathrm{mg}$. $/ 24 \mathrm{hrs}$. (normally less than $120 \mu \mathrm{g} . / 24 \mathrm{hrs}$., the shaded area on the graph). After metyrapone, $750 \mathrm{mg}$. 4-hourly for six doses, the urine free cortisol fell to 345 and $213 \mu \mathrm{g} . / 24 \mathrm{hrs}$. and then rose again to $3 \mathrm{mg}$. On the other hand, the level of 17-oxogenic steroids remained relatively high. Metyrapone reduces cortisol production by inhibition of adrenal 11- $\beta$-hydroxylation, which is essential to its synthesis. Dexamethasone, $2 \mathrm{mg}$. 6-hourly for 8 doses, did not have a very obvious effect on either urine free cortisol or 17-oxogenic steroids. The failure of dexamethasone to reduce cortisol levels suggested that the A.C.T.H. production was ectopic-as was also found by Friedman et al. ${ }^{1}$

The plasma cortisol levels on 22 May were $55 \mu \mathrm{g} . / 100 \mathrm{ml}$. at 9 a.m. (normal (4-21) and $60 \mu \mathrm{g}$. at midnight (normal less than 8). On 12 and 13 June the figures were 56 and 42, respec- 


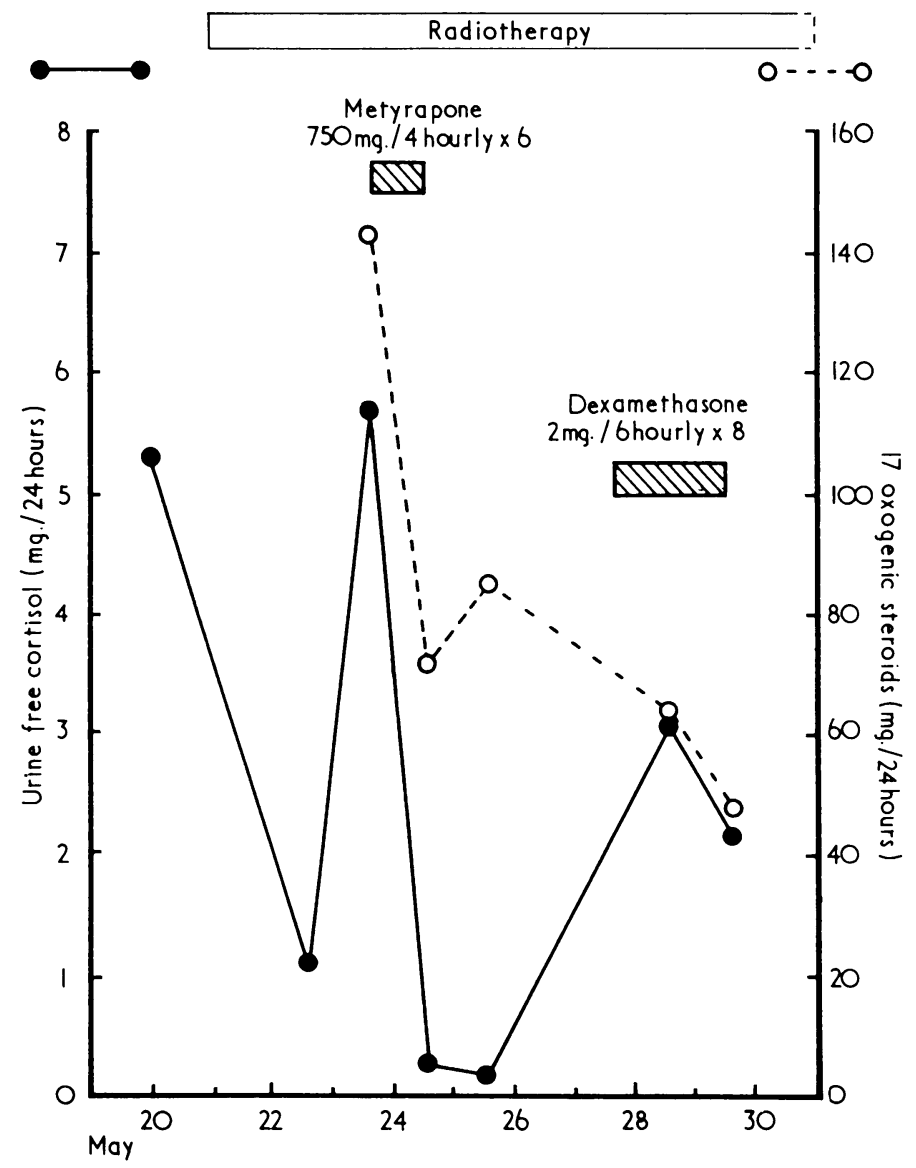

FIG. 3.-Urinary free cortisol and 17-oxogenic steroid levels during hospital admission.

tively, suggesting that though the diurnal rhythm had been lost, there was no significant reduction following radiotherapy.

Other findings on investigation were: serum calcium 4.4 $\mathrm{mN}$; alkaline phosphatase 21 King-Armstrong units; inorganic phosphate $1 \mathrm{mN}$; serum proteins, total $4.5 \mathrm{~g}$., albumin $2.5 \mathrm{~g} . / 100 \mathrm{ml}$. The possibility of ectopic calcitonin production was considered, but these changes are probably related to metastases in the liver. Radiological skeletal survey showed no evidence of metastases in the bone. Though the latter were somewhat thin, they were probably within normal limits. The pituitary fossa was a little deep, but otherwise normal.

\section{Treatment}

The patient was treated with radiotherapy. The diabetes was treated with a $150 \mathrm{~g}$. carbohydrate diet and chlorpropamide $250-375 \mathrm{mg}$. daily with good control. The hypokalaemia was treated with Slow-K. The initial progress was good. Evidence of superior vena caval obstruction disappeared but, despite this and the loss of weight, the patient's face became more obviously rounded. Moreover, the pigmentation increased, especially in the palmar creases, and she became hirsute with growth of hair on the face for the first time ever. After 3 weeks' radiotherapy the tumour became much smaller. After the initial general improvement the patient's condition deteriorated slowly and there was evidence of an enlarging nodular liver. On 17 June unexpectedly and suddenly the patient collapsed and died within a few minutes.

\section{Clinical Diagnosis}

The patient came to necropsy with the clinical diagnosis of oat-cell carcinoma of bronchus producing an A.C.T.H.-like substance. It is interesting to recall that a similar case was presented at a clinicopathological conference here in 1964.2

(1) Oat-cell carcinoma of the lung, producing A.C.T.H.

(2) Cushing-like syndrome.

\section{Post-mortem Findings}

Dr. E. D. Williams (2): There were no external findings of note-in particular, no cutaneous striae were noted. A primary carcinoma was found in the right lung, at the bifurcation of the upper lobe bronchus, forming a mass $2 \times 1.5 \mathrm{~cm}$. which spread from the bronchial mucosa right through the bronchial wall. Two other small deposits of tumour were present in the lungs, one in the right apex posteriorly, and another in the centre of the left upper lobe. Histology of the bronchial biopsy taken in life showed a typical oat-cell carcinoma; the lung tumour showed extensive necrosis, with a few giant nuclei and prominent D.N.A. deposition in small vessel walls (Fig. 4). The widespread metastases in other organs showed typical oat-cell histology (Fig. 5). Otherwise there was confluent bronchopneumonia with abscess formation in the right lower lobe, and scattered bronchopneumonia with abscesses in the left lower lobe. Many Gram-positive cocci were seen in sections from these areas; and in one a focus of fungal infection, probably aspergillosis, was seen (Fig. 6). In the alimentary system there were two small gastric erosions; the liver

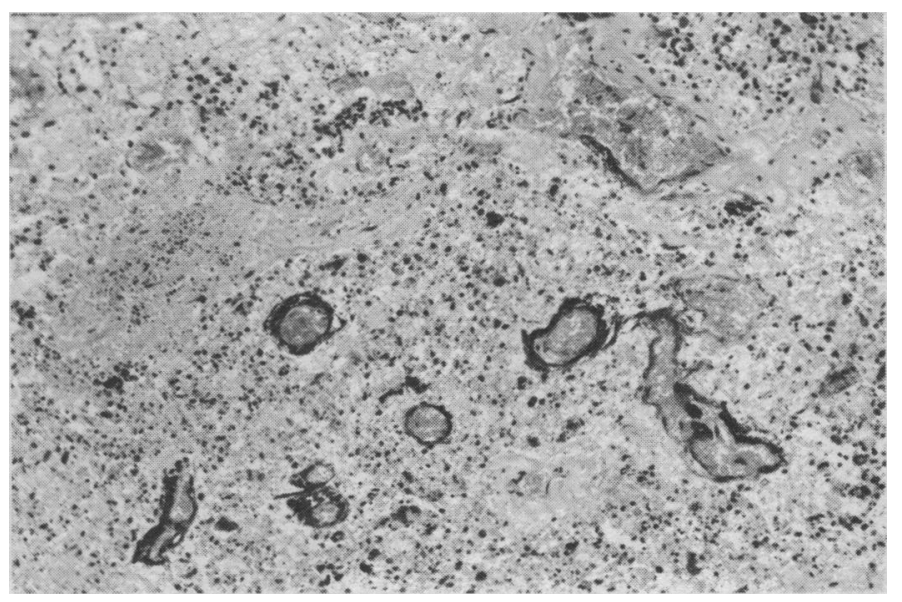

FIG. 4.-Necrotic oat-cell carcinoma of lung showing D.N.A. encrusted vessel walls. (H. and E. $\times 100$.)

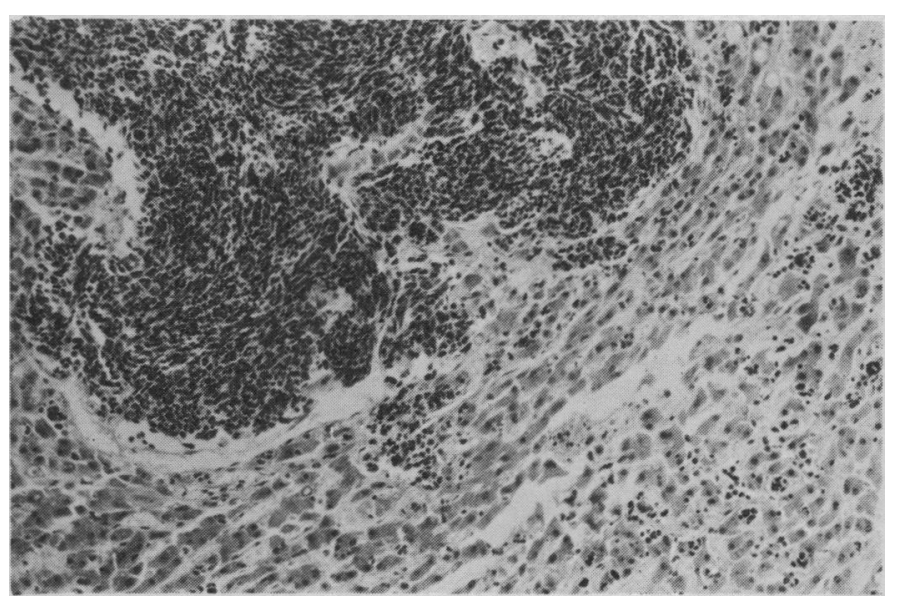

Fig. 5.-Metastatic oat-cell carcinoma to liver, forming a large deposit but also infiltrating sinusoids. (H. and E. $\times 100$.) 


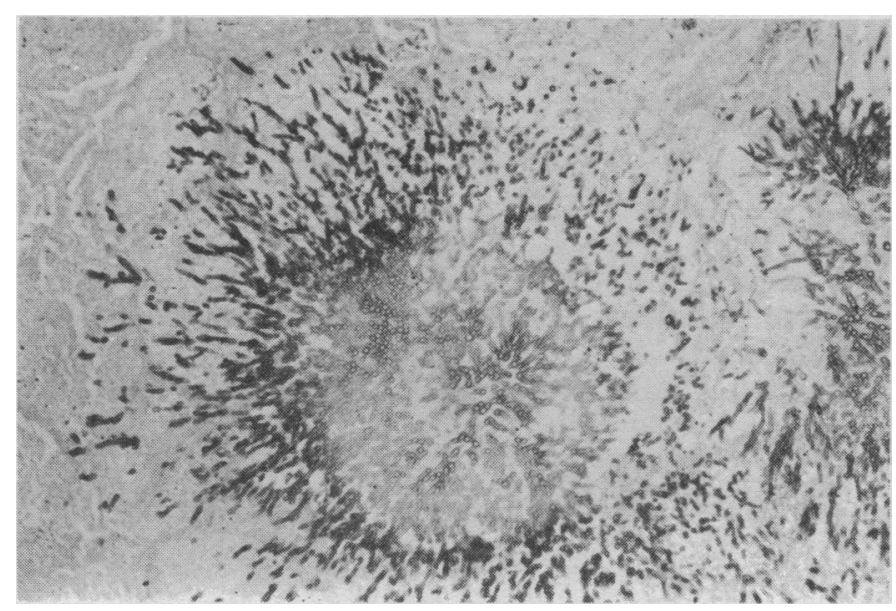

Fig. 6. - Colony of aspergillus in necrotic lung tissue. $(H$. and $E . \times 100$.)

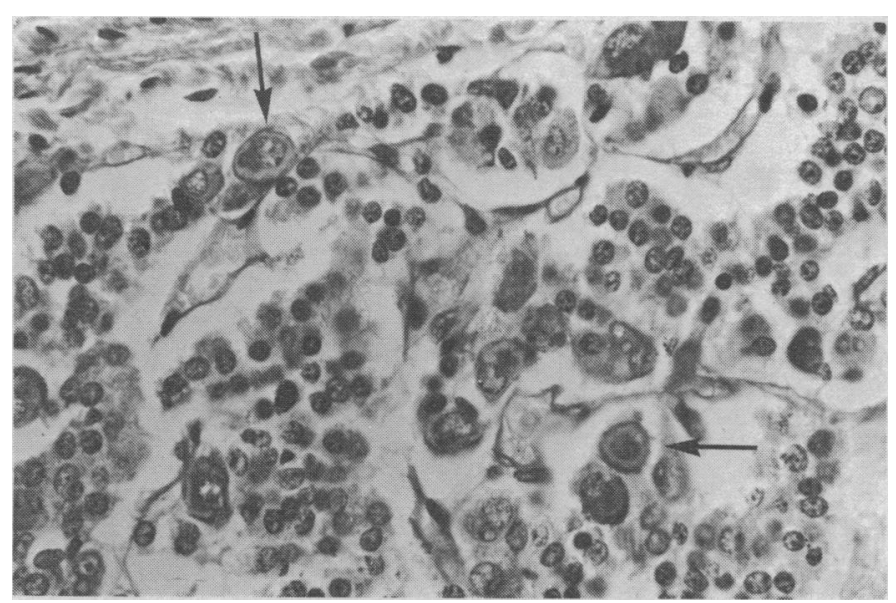

FIG. 7.-Pituitary showing several Crooke cells (arrowed). The hyaline ring around the nucleus is often surrounded by an outer layer of granules. (Periodic acid Schiff $\times 415$.)

and the pancreas showed many scattered deposits of pale grey secondary carcinoma. An area of fat necrosis was present extending from the tail of the pancreas to the hilum of the left kidney.

In the endocrines the pituitary contained small deposits of secondary carcinoma in both anterior and posterior lobes. Crooke cells were numerous (Fig. 7). The thyroid was small $(8.5 \mathrm{~g}$.$) , and showed a severe focal thyroiditis with extensive$ oxyphil change. One small metastasis was present. Both adrenals were enlarged ( $9 \mathrm{~g}$. each) and both showed severe cortical hyperplasia; the cortices were thickened, with compact cells extending out to the capsular area (Figs. 8 and 9); a few islands of foamy cells survived.

In the reticulo-endothelial system secondary carcinoma was present in many lymph nodes, and in many microscopic deposits in the spleen and spinal marrow. The vertebrae showed moderate osteoporosis. The genitourinary system showed few abnormalities; both kidneys were normal; a calcified myoma was present on the fundus of the uterus.

\section{Pathologist's Diagnosis}

(1) Oat-cell carcinoma of right upper lobe of lung.

(2) Metastases to liver, lymph nodes, bones, adrenal, pancreas, spleen, thyroid, and pituitary.

(3) Bilateral adrenocortical hyperplasia.

(4) Crooke-cell change in the pituitary.

(5) Osteoporosis.
(6) Bronchopneumonia with abscess formation.

(7) Aspergillosis.

(8) Fat necrosis of tail of pancreas.

(9) Severe focal thyroiditis.

Dr. Poole : I hope to hear from Dr. C. W. Burke more details of the urine estimations which I think show without doubt that, after treatment with metyrapone, the urinary cortisol fell precipitously (which suggests that the drug was intertering with $11-\beta$-hydroxylation in the adrenals, and therefore reduced the amount of cortisol), but that after dexamethasone there was no suppression at all. This strongly suggests that there was an ectopic production of A.C.T.H. which was not mainly dependent on the pituitary.

Just to widen the discussion I would like to show a table. During the last four or five years, Dr. Feeman, Dr. Azzopardi, and myself have been collecting data from patients with bronchial carcinoma who have come into our ward through the chest clinic-in all totalling 185 with histological proof. Of these $8.6 \%$ had endocrine syndromes (Table). The incidence of gynaecomastia may be an underestimate, since we did not investigate histologically an appreciable number of patients, the assessment being largely clinical. Again, the number of patients with hypercalcaemia may also be underestimated since some patients were not followed until they died.

Our study confirms the association between hypercalcaemias and squamous carcinoma. In this series, oat-cell carcinoma accounted for only one of the eleven instances of hypercalcaemia: combining this with the figures given by Azzo-

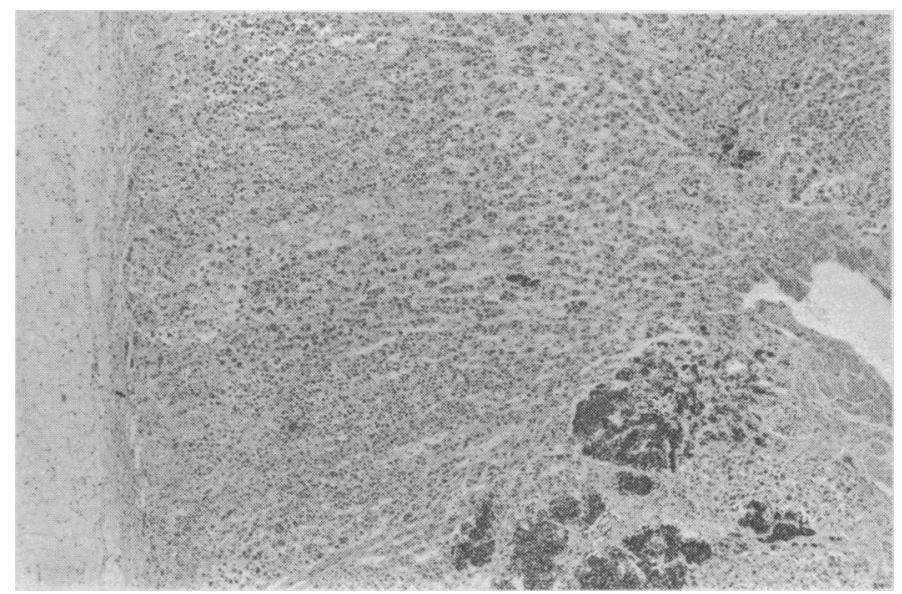

FIG. 8.-Adrenal showing broad active cortex and metastatic carcinoma. (H. and E. $\times$ 28.)

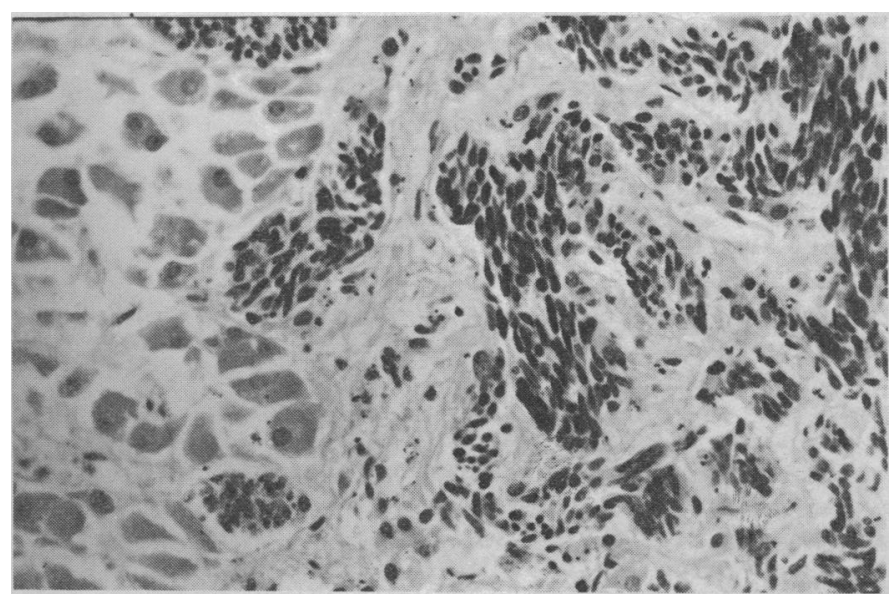

Fig. 9.-High-power view of adrenal metastasis with adjacent large stimulated "compact" cells of the cortex. (H. and E. $\times 415$.) 
pardi and Williams, ${ }^{3}$ only three of the twenty-nine cases of hypercalcaemia in carcinoma of the bronchus were due to oat-cell tumours. As in the case we are discussing today, Cushing's syndrome is probably always associated with oatcell carcinoma or perhaps carcinoid tumours.

Frequency of Endocrine Syndromes (8.6\% Total excluding H.P.O.A.) In 185 Consecutive Histologically Proved Cases

\begin{tabular}{l|c|c}
\hline \multicolumn{1}{c|}{ Endocrine Anomaly } & Number & Percentage \\
\hline Hypercalcaemia & 11 & 5.9 \\
S.I.A.D.H. & 3 & 1.6 \\
Cushing's Syndrome & 1 & 0.5 \\
Gynaecomastia & 1 & 0.5 \\
H.P.O.A. & 3 & 1.6 \\
\hline
\end{tabular}

Professor C. C. Booth (3): I had the impression that these syndromes were commoner than you imply. The problem is that one sees only the unusual cases at demonstrations and comes away with the feeling that every patient with carcinoma of the lung has one of these complications. Could we start with the endocrinological problems? Dr. Burke, would you like to do this?

\section{Absent Diurnal Rhythms}

Dr. C. W. Burke (4): Dr. Poole's chart showed the very high levels of plasma cortisol and the absent diurnal rhythm-findings which suggest Cushing's disease. Despite the variability in the oxogenic steroid excretion, we were able to confirm the presence of severe Cushing's disease chemically by measuring the urinary free cortisol excretion, which was over $5 \mathrm{mg}$. in 24 hours. This is 50 times the upper limit of normal.

We were also able to suggest the cause of this over production of cortisol by what is often called dynamic testing. This was done-as Dr. Poole mentioned-by suppression with dexamethasone. Normally speaking, a patient with pituitarydependent Cushing's disease (that is, over-production of A.C.T.H. from the pituitary causing adrenal hyperplasia) will show suppression of cortisol production after being given 8 mg. dexamethasone per day. This patient showed no such reduction in steroid output and maintained a very high urinary free cortisol output in the face of dexamethasone administration, a finding which suggests that the pituitary was not involved in the Cushing's disease in this patient.

The other test which was done was to give metyrapone, a substance which inhibits the synthesis of cortisol at a late stage by the adrenal. In normal people the pituitary secretion of A.C.T.H. rises in an effort to restore the situation, and this is also true in patients with pituitary-dependent Cushing's disease.

One would expect, therefore, that with increased A.C.T.H. production urinary steroid excretion would rise owing to the accumulation of precursors of cortisol. In this particular instance there was a definite fall in the excretion of free cortisol and its precursor compound S. All the evidence here is that it was a severe non-pituitary-dependent disease. An adrenal adenoma may behave the same chemically but obviously in the presence of a lung tumour with the characteristic changes of hypokalaemic alkalosis then this is all likely to be due to the lung tumour.

Professor Booth: You are implying that the tumour is producing something which is stimulating the adrenals directly, not through the pituitary?

Dr. BuRkE: Yes, on our evidence. We have no direct evidence that this was A.C.T.H. from the tumour, but there seemed to be no excess A.C.T.H. from the pituitary nor any adrenal tumour at necropsy.

\section{Mechanism of A.C.T.H. Production}

Dr. Williams: This mechanism is certainly found in most cases that have been fully investigated. Liddle and his group in Tennessee 4 have shown that the A.C.T.H.-like substance produced by these tumours is virtually identical with pituitary A.C.T.H., though I have not yet read of a full amino-acid sequence being determined on A.C.T.H. extracted from these tumours. Also the pathological findings in this case-the presence of adrenal hyperplasia, the absence of a pituitary adenoma, and the presence of a tumour known to make A.C.T.H.-like material-make it virtually conclusive that this is the correct explanation of the Cushing syndrome here.

Dr. Martin Hartog (5): Could I just say something about the presentation of this patient? As you heard, the question of Cushing syndrome really arose because of the very low potassium level that was found on screening. It was quite difficult to find any clinical evidence that she had Cushing's syndrome. The only possibly relevant symptoms were polyuria and polydipsia, which may have been related to her glycosuria or to the hypokalaemia. Quite commonly in these carcinomatous Cushing's syndromes the usual manifestations of the syndrome are occult.

Another way that the patients can present is with mental changes. $^{2}$ These patients become very confused and this has led to diagnostic difficulties and suspected intracranial secondaries. In fact, these mental changes are almost certainly due to the extremely raised cortisol secretion.

With the present patient we were confident that she had biochemical Cushing's syndrome, and in fact there was the carcinoma demonstrable on an $x$-ray film of the chest But, even so, there may be a very real diagnostic difficulty in patients in whom no carcinoma has been found on the chest $x$-ray. In one patient in a series reported from University College Hospital the neoplasm was shown only at necropsy, though the existence of such a tumour was strongly suspected because of the presence of hypokalaemic alkalosis and diabetes, and some other clinical features of Cushing's syndrome.

One other point that has been stressed by almost everybody describing such cases is the extremely poor prognosis of the bronchial carcinoma when it is associated with biochemical or clinical Cushing's syndrome. The mean period of survival in the 9 or so patients from U.C.H. from the day they were first seen was about 24 days in the patients who had evidence of Cushing's syndrome, contrasting with a much longer period of survival in patients with no such evidence.

\section{Is Cushing's Syndrome Missed ?}

Dr. Williams: Dr. Hartog has really been commenting on those patients who present with obvious Cushing's syndrome. The smallest recorded ectopic A.C.T.H.-producing tumour was a bronchial carcinoid which weighed only $600 \mathrm{mg} .^{5}$ That is just to underline the point that occasionally the tumours can be very small, and are not picked up. How often is Cushing's syndrome, or other endocrine manifestations, missed in patients with carcinoma of the lung? Cushing's syndrome in these patients may be overlooked, particularly if the serum potassium is not estimated, or the significance of a high levei not appreciated.

Professor Booth: That cannot be the case in Dr. Poole's series because he has been measuring serum potassiums in all cases.

Dr. POOLE: That is correct because we have been screening these patients over the last four or five years. I doubt if we have missed any with hypokalaemic alkalosis and, of course, most of these cases do present with hypokalaemic alkalosis, and not with any clinical features of Cushing's syndrome as such. Even so, I think this patient-terminally at least- 
showed some physical signs that might have suggested Cushing's syndrome.

Dr. Williams: Most people would accept that hypokalaemic alkalosis is caused by grossly excessive steroid production. Surely some tumours must fall into the intervening group where they make as much steroids as you find in the normal Cushing's syndrome (if I can call Cushing's syndrome normal) but not enough to cause this gross hypokalaemic alkalosis. How about those? You are not picking those up.

Dr. Poole: How shall we pick them up if we are not to depend on physical signs or hypokalaemic alkalosis? Would you like us or our colleagues to do a cortisol level in every case?

Dr. Williams: Yes.

Dr. BURKE: There are large series reporting over 100 cases from America where the incidence of steroid abnormalities has been studied, but if the patients are shown to be unstressed it is very low indeed. ${ }^{6}$

Dr. D. C. Anderson (6): One pitfall, which I have certainly seen once or twice, is the over-hasty interpretation of hypokalaemic alkalosis in this situation. This, of course, is commonly a presenting symptom of hypercalcaemia, though this is not in question here. I think it is important to estimate the calcium level as well as the other electrolytes on all these patients.

\section{Calcium Metabolism}

Professor Boотн: Now what about the serum calcium level? We have a level of $4.4 \mathrm{mN}$, and somebody writes down: "query calcitonin production." In the series that Dr. Poole described I think the commonest problem was hypercalcaemia. Was there any hypocalcaemia in any of these patients, and do you ever get calcitonin from any of these tumours?

Dr. Williams: I do not know Dr. Poole's figures on the incidence of hypocalcaemia. Since the ectopic production of hormones is becoming very fashionable, obviously we are looking for calcitonin production by other tumours. So far we have not found any firmly documented case. There are one or two tumours we have found which show immunoreactive calcitonin, but so far this has not been confirmed on bioassay.

As regards this patient I would have thought that the mundane explanation that the serum proteins were low was by far the best explanation of the hypocalcaemia.

Professor Booth: That seems very fair. Now you have shown us some very striking changes in the thyroid. What are these due to, and how often does one find them in a routine necropsy?

Dr. Williams: Focal thyroiditis is very common, particularly in women, and particularly in postmenopausal women. Therefore, this patient falls into the high-risk group. It is not uncommon to find this degree of focal thyroiditis in an elderly woman, and it is not uncommon to find a thyroid as small as this-I think it was $9 \mathrm{~g}$. This presumed autoimmune disease cannot be linked with any of the other facets of this patient's illness. It has been correlated with a high incidence of circulating thyroid antibodies in studies where the correlation between histology and antibodies has been made.

Professor Booth: This is the incidence at necropsy?

Dr. Williams: It is fairly common. Professor Doniach and I found that $10 \%$ of women of this age group showed very severe focal thyroiditis of this degree. ${ }^{8}$

Dr. N. J. WoodHouse (7): It has been suggested that a low calcium level suggests excess calcitonin production. We have investigated several patients with medullary carcinoma of the thyroid, who secrete large amounts of calcitonin, and the serum calcium levels are always normal-or at least they have been in our series. A low calcium level does not necessarily mean that there is excess calcitonin production. Certainly a normal calcium does not exclude it.
I would like to ask about the parathyroids in this case because in two of our patients with excess calcitonin production there were increased parathyroid hormone levels.

Dr. Williams: The parathyroids were normal in size, and contained the amount of fat normal for patients of this age. I would agree that this would be a point against calcitonin production.

Professor Booth: Turning now to the tumour itself, one of the striking features is this cuff of D.N.A. that you were showing around the vessels. Why does this happen?

Dr. Williams: This is not specific for oat-cell carcinoma, but is much more commonly found in oat-cell carcinoma than in other tumours. It seems simply to reflect the loss of a large relative amount of D.N.A. from the nuclei. Why it should stick to vessel walls I do not know, but this observation was made originally by Dr. Azzopardi ${ }^{9}$ and has since been confirmed many times over.

Dr. Poole: Would it be valuable to examine the tumours concerned in these endocrine syndromes for the appropriate hormones?

Dr. WILliams: Certainly one would like to have hormone assays. I suspect that if one were to do them on various different tumours one would find that small amounts of ectopic hormone production are much more common than we realize from the clinical presentation-which obviously depends on the production of a great excess of the hormone concerned.

\section{Why are Ectopic Hormones Produced?}

Another point I would like to stress is the non-random nature of the production of these ectopic hormones. This is something that Dr. Azzopardi and I have worked on together as far as A.C.T.H. is concerned, and we have pointed out that A.C.T.H. production occurs with certain specific tumour types. $^{2}$ The commonest of these is oat-cell carcinoma of the lung. However, A.C.T.H. production is virtually unrecorded with adenocarcinoma or squamous-cell carcinoma of the lung, which are much commoner than oat-cell carcinomas.

The only other lung tumour which may occasionally produce A.C.T.H. is the bronchial carcinoid-which is probably related to the oat-cell carcinoma, and may well arise from the same cell of origin. Outside the lung A.C.T.H. production occurs with medullary carcinoma of the thyroid, and with a specific histological pattern of thymoma. It occurs rarely with gastric carcinoids and rather more commonly with pancreatic islet-cell tumours. There is a small second group of A.C.T.H. production by phaeochromocytomas and related tumours, and a third, even smaller, group of occasional ovarian tumours making A.C.T.H. Outside those three major groups there are very few tumours recorded as making A.C.T.H.

Parathyroid-like hormone production by tumours does not show the same histological specificity. It occurs with a wide variety of tumour types, though it tends to occur more commonly with squamous carcinomas than with other types. Antidiuretic hormone, if anything, seems to follow the A.C.T.H. pattern.

The significance of all this is unknown, but at least one can say that this ectopic hormone production is not due to the random de-repression of D.N.A. One can try and explain this in terms of molecular biology, which seems a very rational approach. Of course, in a tumour which becomes more and more anaplastic any bit of the D.N.A. can get derepressed, and in theory any tumour is capable of forming any substance normally manufactured by the body.

The point of these histological studies is that this random de-repression does not occur-that is, certain specific tumour types make certain specific hormones relatively commonly, while others do not. 


\section{Repression of Cell Function}

Professor Воотн : Where you have specialization of cells, is the genetic make up (that is, the D.N.A. content) the same in all cells in the body, so that all cells have the potential of making certain substances if they have the chance? Are some functions repressed in some cells and not in others?

Dr. Williams: Yes, this is all true, and almost dogma these days. Probably the best single piece of evidence to support this is provided by Gurdon. ${ }^{10} \mathrm{He}$ put the nucleus from a differentiated tadpole intestinal cell into an enucleated frog ovum. Out of that "ovum" developed an absolutely normal adult frog. In other words, the D.N.A. that was present in a differentiated intestinal cell contained within it all the requisite sequences to give rise to all the tissues in the body.

Professor Booth: This is fine in terms of chromosomes and D.N.A. Is it equally true for the R.N.A. system within the cell?

Dr. Williams: If you accept the Jacob-Monod theory then your messenger R.N.A. itself is coded for by D.N.A. So it does not matter too much-everything is dependent on D.N.A.

The Jacob-Monod theory is perhaps getting whittled away slightly, particularly with the evidence of small amounts of D.N.A. present in mitochondria. Some authorities also now say that there may be very, very long-lived R.N.A., which may also be important in terms of control of differentiation.

In general, however, I think one would still believe that the nuclear D.N.A. contains within it everything necessary for the production of all the substances found in the cell.

Professor Booth: But given something going wrong with the cell there is no reason why a cell should not produce anything then?

Dr. Williams: That is true, but why should certain specific tumour types produce certain specific hormones-like oatcell carcinoma and A.C.T.H., squamous carcinoma of the lung and parathyroid-like hormone? There is some message here about the state of the D.N.A. in the normal differentiated cells from which these tumours arise.

Professor Booth: Thank you very much. Any other points?

Dr. HARTOG: Could I just say a word about the treatment of these carcinomatous Cushing's syndromes? The overall prognosis of these patients is very poor, and though treatment can affect the Cushing's syndrome, the effect on mortality has not been striking. One can improve the Cushing's syndrome either by adrenalectomy (a considerable undertaking in these sick patients), or by giving drugs such as metyrapone. In the short period that it was given in the present patient it blocked cortisol synthesis. There is also another drug called aminoglutethimide (or Elipten) which will block cortisol synthesis.

Professor Booth: I think we ought to conclude with a word on aetiology from Dr. Fletcher.

Dr. Charles Fletcher (8): Well, this lady had smoked 15 cigarettes per day, and had done so for 25 years. So one need not look elsewhere for any aetiological factors. She presumably had lived in London, and it may be that there was a small contribution from air pollution of our cities. This is rather uncertain, but $I$ think most people think that there is a contribution from air pollution. The fact that cancer of the lung is an occupational disease, as well as a smoking and air pollution disease, is important because it does add emphasis to the fact that this is a very, very rare tumour to occur spontaneously. It may be produced by a whole variety of chemical agents, nearly always introduced to the lung by inhalation.
What surprises me, and I do not know if the pathologists have any ideas about this-I have never heard any-is why this probably main, single aetiological agent of cigarette smoking can produce two totally diverse types of tumour, the squamous and the oat-cell, both of which are equally related to smoking?

\section{Cause of Death}

Professor Booth: Dr. Williams, this patient died suddenly, unexpectedly, and for no apparent reason. Why did she die?

Dr. Williams: We failed to find any of the usual causes of sudden death. There were no major pulmonary emboli, there were no coronary occlusions. The only very recent phenomenon, apart from the bronchopneumonia, was the presence of the fat necrosis. I do not myself see why either the bronchopneumonia or the fat necrosis should account for such a dramatic sudden death.

Under these circumstances we usually resort to saying that this must have been a "biochemical" death. We do not see why structural abnormalities should be expected to explain absolutely everything!

Professor Booth: Dr. Poole, why did the patient die suddenly? Neither of you have explained this.

Dr. Poole: I cannot explain it either, but obviously there were several contributory factors. The potassium was rather low, and had been off and on during her illness. Evidently her resistance was poor. The protein electrophoretic strip showed a low $\gamma$-globulin. As you heard, she had quite obvious evidence of infection in the lungs which was not being controlled.

The day before she died there was an episode of pain in the right hypochondrium, apparently in the liver, where there were many metastases.

Professor Booth: I think we have to accept that we do not know why this patient died suddenly, however much we may think we know about the synthesis of steroid hormones.

\section{APPOINTMENTS OF SPEAKERS}

(1) Dr. G. W. Poole, Consultant Chest Physician, Honorary Lecturer, Royal Postgraduate Medical School.

(2) Dr. E. D. Williams, Reader, Morbid Anatomy, Royal Postgraduate Medical School.

(3) Professor C. C. Booth, Professor of Medicine, Royal Postgraduate Medical School.

(4) Dr. C. W. Burke, Senior Registrar, Department of Medicine, Royal Postgraduate Medical School.

(5) Dr. Martin Hartog, Senior Medical Registrar, Hammersmith Hospital.

(6) Dr. D. C. Anderson, Research Assistant, Department of Medicine, Royal Postgraduate Medical School.

(7) Dr. N. J. Woodhouse, Research Assistant, Department of Medicine, Royal Postgraduate Medical School.

(8) Dr. Charles Fletcher, Reader, Clinical Epidemiology, Royal Postgraduate Medical School.

\section{REFERENCES}

1 Friedman, M., Marshall-Jones, P., Ross, E. J., Quarterly fournal of Medicine, 1966, 35, 138, 193

Clinicopathological Conference, British Medical fournal, 1965, 1, 708. Azzopardi, J. G., and Williams, E. D., Cancer (Philadelphia), 1968, 22. 274.

Liddle, G. W., Island, D. P., Ney, R. L., Nicholson, W. E., and Shimizu, N., Archives of Internal Medicine, 1963, 111, 471.

strott, C. A., Nugent, C. A., and Tyler, F. H., American fournal of Medicine, 1968, 44, 97.

6 Lichter, I., and Sirett, N. E., British Medical fournal, 1968, 2, 154.

Goudie, R. B., Anderson, J. R., and Gray, K. G., fournal of Pathology and Bacteriology, 1959, 77, 389.

8 Williams, E. D., and Doniach, I., fournal of Pathology and Bacteriolozy, 1962, 83, 255.

9 Azzopardi, J. G., Fournal of Pathology and Bacteriology, 1959, 78, 513. 10 Gurdon, J. B., fournal of Embryology and Experimental Morphology, $1962,10,622$. 